\title{
Advanced English language acquisition and application in specialized subject areas
}

\author{
Lucia Taylor \\ luciataylor79@yahoo.ca \\ UNIVERSITÉ PARIS — SORBONNE
}

\begin{abstract}
Students in courses on specialized subjects may have different levels of proficiency in the English language. In such situations, the instructor should endeavour to adopt a holistic teaching approach to promote understanding of the course content along with enhancement of English language skills. Best practice methods based on years of practical experience in the delivery of specialized courses at an advanced level will be described. A sociological approach and the application of sociological terms are intended to show how instructor engagement and efficacy are essential to advancing the language capabilities of non-native English speaking students.
\end{abstract}

Key words: second language acquisition, specialized subjects, social sciences

\section{Résumé}

La fonction que remplit l'enseignant de cours de matières spécialisées auprès d'étudiants ayant des compétences variées en anglais s'inscrit dans une approche pédagogique globale visant à promouvoir la compréhension du contenu spécialisé et l'amélioration des compétences linguistiques en anglais. Des méthodes découlant de pratiques exemplaires sont décrites et ressortent de nombreuses années d'expérience empirique de l'enseignement de matières spécialisées au niveau supérieur. L'approche sociologique et l'application de concepts sociologiques visent à démontrer que l'engagement et la compétence de l'enseignant sont essentiels pour améliorer les capacités linguistiques d'étudiants locuteurs non natifs de l'anglais.

Mots-clés : acquisition de langue seconde, matières spécialisées, sciences sociales 


\section{Introduction}

The delivery of specialized courses at an advanced level requires an understanding of diverse class composition to leverage individual and group qualities and optimize classroom experience. Class participants are pluralistic, as individual students have different interests, knowledge, experiences and backgrounds; they represent a range of discourse communities (i.e. differing norms, standards, rules, verbal and non-verbal symbols) and display differences in social cognition. Hence, processing and understanding of information as well as interaction will take place in various ways and through different perspectives. Furthermore, students' diverse learning mechanisms will vary (some need to be shown, some are more independent, some require additional instructor ${ }^{1}$ guidance, some prefer peer explanation or visual aids and others written instructions). Finally, different language capability levels can influence peer-to-peer interaction and the extent to which peer instruction is effectuated.

Instructors of specialized subjects are essentially the "last port of call" for non-native English speaking students prior to their seeking entry into employment, where they will be applying interpersonal soft skills (primarily language competencies) as well as specialized know-how. While non-native English speaking students might have guidance in technical and practical application within their specialized courses, learning material to develop further language skills is often left out of the curricula of specialized courses. Specialized course books (in subjects such as sociology, psychology and nursing) are written for the native or highly proficient speaker of English with a view to delivering understanding of specific subject areas (and do not include language advancement sections for non-native speakers).

Given that the language proficiency of students in specialized courses varies, in-class activities should combine understanding of content together with enhancement of the relevant soft skills, notably oral and written expression for non-native English speakers. Such an approach will optimize their chances of finding the right fit in choosing a career. Writing for the online news site Canadian Immigrant, Jetelina (2012) describes the communication soft skills demanded in Canadian workplace culture:

Oftentimes what employers mean when they say they are looking for Canadian experience is that they are looking for someone who has the same core social competencies as any Canadian, for example the ability and potential to form Canadian relationships and knowing how to employ a Canadian communication style effective [sic].

(Jetelina, 2012)

\footnotetext{
${ }^{1}$ The term "instructor" also encompasses other relevant terms, such as "professor", "lecturer", "teacher" or "facilitator".
} 
Instructor knowledge and guidance should extend beyond a student's shortterm goal of passing the course on the sole basis of knowledge of the specialized subject. Classroom activities should provide vital elements that enhance cognitive skills and social aptitudes for social and professional integration and help fulfill individual visions and goals. Key abilities for success in external environments can form part of the classroom experience. They include leadership skills such as those described by Goleman (2004, p. 82ff):

(i) "self-awareness" (applying inner reflection regarding various issues or topics)

(ii) "empathy" and "social skills", i.e. competencies enabling group and team interaction, and finally

(iii) "motivation" linked to acquiring valuable or unique talents.

The author of this article affirms that such leadership qualities can enhance the understanding and capabilities in their future careers that students need to be "equipped and trained to communicate effectively with all walks of life" (Gill, 2010, p. xiii). Leadership styles differ among cultures; hence, awareness of the way leadership is perceived within a specific culture is part of linguistic and socio-cultural understanding (pp. 171, 265).

Development of interpersonal soft skills is related to students' language proficiencies, which the specialized course instructor should aim to develop. Indeed, discourse and meaning are never produced in isolation but primarily reflect " ' information from the social system' that is, messages 'about different degrees of hierarchy, inclusion and exclusion, boundaries and transactions across boundaries'" (Douglas, 1975, cited in Frow, 1980, p. 79).

The specialized language teacher needs to ensure that language advancement within the classroom involves acquiring language skills that show students' specialized (or technical) understanding and their socialization, i.e. qualities that demonstrate they have internalized "the norms and values of society" and have learned to perform "social roles (as worker, friend, citizen and so forth)" (Scott and Marshall, 2009, p. 714). In this context, Govinder Gill, Canadian author of Achieving prosperity through diversity (2010), states in an interview regarding Canadian workplace culture, "[T] he hiring person is asking themselves 'Will this new person fit in the company's working environment?' After all, the employer is not only seeking jobs skills, but also inner qualities that will make the applicant a great team player' "ts" (Jetelina, 2012).

Here, leadership abilities, such as speaking with purpose, writing effectively, establishing relationships and managing conflict and change (Neuhaus et al., 2004), are associated with language competencies and demand specific socio-cultural awareness. Dr. Lionel Laroche, an educational speaker, points 
out that "gaining the soft skills needed to succeed is one of the biggest issues immigrants have in the Canadian labour market" (Jetelina, 2012, interviewing Laroche). Instructors of specialized subjects are the "last port of call" for nonnative English speaking students to improve culturally bound discourse skills, i.e. before experiencing the professional environment.

The author of this article suggests that the motivation for non-native English speaking students to apply themselves to mastering specialized content and improving language capabilities is linked to their resilience and tenacity in their desire to succeed socially and professionally. These qualities in turn promote confidence in the ability to overcome challenges, notably when a lengthy process (such as language learning) is involved. This assertion reflects the findings of Duckworth et al. (2007), later supported by Christensen and Knezek (2014), who investigated why certain individuals succeed over others of equal intelligence in a diverse range of fields. Duckworth et al. concluded that "grit", also described as "perseverance" and "tenacity" (pp. 1087, 1089), "entails working strenuously toward challenges, maintaining effort and interest over years despite failure, adversity, and plateaus" - qualities that can essentially determine ultimate success (pp. 1087-1088).

In general, the instructor should fulfill a role as facilitator or "intermediary" (Code, 2010:27) and encourage the development of "collective efficacy" (Bandura, 2001, pp. 1). Here, the facilitator can promote an "interactive", "coordinated" and "collective" performance (p. 14) of students" activities whereby course content (on specialized subject themes) is developed into broader interrelated themes to give students the opportunity to dialogue and interact on events in the external environment.

Hence, the instructor's delivery and interactions to promote student "grit" or perseverance in the advancement of language competencies should take into account Bandura's assertion relating to "collective efficacy" (2001, pp. 1):

[T] he stronger the perceived collective efficacy, the higher the groups' aspirations and motivational investment in their undertakings, the stronger their staying power in the face of impediments and setbacks, the higher their morale and resilience to stressors, and their greater performance accomplishments.

\section{Addressing differences in language capabilities}

The delivery of courses on specialized subjects cannot be accomplished effectively within the framework of a "one-size-fits-all" approach given the multitude of interconnecting variables factored into class composition. While nonnative English speakers can acquire significant specialized language competencies in English through instructor delivery, they should also develop proficiency through peer-to-peer interaction and guidance (with both native and non-native English speakers). Peer engagement contributes to the quality and 
worth of their classroom experience (Brame, 2013; Code, 2010, pp. 113-114; Turner, 2006, p. 145), and non-native English speakers can further their language skills within the socio-cultural interaction of classroom activities. Here, individual students can benefit from the opportunity that Bandura (2001) describes as "proxy agency" (pp. 1) where one (e.g. the individual student) "relies on others to act on one's behest to secure desired outcomes" (p. 1).

Classroom experience is not designed to be a learning event that takes place in isolation; indeed, many specialized courses lend themselves well to the "flipped class" approach (Brame, 2013) whereby students carry out required reading and exercises outside of class time and are given the opportunity to "spend time in class engaged in debates, data analysis, or synthesis activities (...) using class time to deepen their understanding and increase their skills at using their new knowledge" (Brame, 2013). The author of this article can assert from practical experience as an instructor of specialized courses that nonnative English speakers can significantly improve general, specialized and culturally specific language competencies through active instructor involvement as well as through the peer-to-peer interaction that a "flipped class" incorporates (Brame, 2013).

Students should therefore be given the opportunity to turn to team peers for additional guidance, through a process Bandura has referred to as "proxy agency" (Code, 2010, p. 27), which could entail, for example, the delivery of culturally relevant soft skills in group activities. Such a process can enhance the language skills of non-native English speaking team cohorts. Bandura (2001, p. 13) describes the importance of the "proxy agency" required for different areas of interaction in which

[s]uccessful functioning necessarily involves a blend of reliance on proxy agency (...). People also turn to proxy control in [certain] areas $(. .$.$) when (\ldots)$ they believe others can do it better (...). Hence they have to work in coordination with others to secure what they cannot accomplish on their own.

Indeed, peers exercising "proxy agency" within the classroom contribute to a classroom learning culture in which students can internalize knowledge from peers as much as (and sometimes even more than) from formal instruction (Code, 2010, pp. 113-114). This process reflects the indirect culture of the Canadian workplace, which values employees who learn from peers and build respect through peer-to-peer interaction, the latter regarded as a key principle for career promotion (Adolphe, 2013, p. 56). 


\section{Best practice methods}

\section{Introduction}

Generally speaking, much of the specialized terminology in such fields as sociology, nursing, hospitality, business and communications is new to both native and non-native speakers. However, non-native English speakers have an added disadvantage in that their use of the language is often not on the same level as that of native speakers. Therefore, non-native speakers might not be able to assimilate newly learned terms and concepts within grammatically correct contexts as readily as their native English-speaking counterparts. Furthermore, non-native English speakers might face challenges in applying terminology within a relevant socio-cultural framework, as discussed in the following section dealing with socio-cultural understanding of the English language in specialized courses.

\section{Language acquisition as part of social and cultural understanding}

The specialized course instructor's role as "mediator" through the delivery of relevant information (Code, 2010, p. 48) is further extended to include the development of culturally appropriate application of language functions (i.e. why we communicate, such as using language in persuasion, questioning or expressing consent.) and speech acts (i.e. utterances that have a purpose, such as expressing apology, thanks, dislikes or likes). Celce-Murcia et al., (1995) define language functions as encompassing "seven key areas: interpersonal exchange, information, opinions, feelings, [per]suasion [sic], problems, and future scenarios" (Celce-Murcia et al., 1995, p. 20). All of these are required to be able to thrive in daily communication.

As the "last port of call" for students before they enter the working world, the instructor can enrich the language competencies of non-native English speaking students by focusing on specific features of language, such as language functions that are often neglected in foreign language learning material (Celce-Murcia et al., 1995, p. 20). An inability to communicate effectively, in the working environment in particular, can result in disappointment, frustration or even failure and will inevitably erode individual determination, personal resilience and "self-efficacy", defined as individuals' confidence in their ability to achieve and ultimately to succeed (Bandura, 2001, p. 10).

Encouraging socio-cultural understanding of language, which reflects discourse patterns, strategies and interactions with the external world, is essential to enhance students' awareness of communication styles within the Canadian work environment. Celce-Murcia et al., (1995, p. 23) define language use in relation to socio-cultural understanding as

the speaker's knowledge of how to express messages appropriately within the 
overall social and cultural context of communication, in accordance with the pragmatic factors related to variation in language use. These factors are complex and interrelated, which stems from the fact that language is not simply a communication coding system but (...) the most important channel of social organization, embedded in the culture of the communities where it is used.

Yet, as Celce-Murcia et al., (1995) note, there are challenges stemming from the complexities of transferring the language learnt or studied onto actual "real-life communication" (p. 23). Class activities in specialized subjects should thus develop linguistic competencies relating to socio-cultural awareness and contextual understanding, as non-native English speakers' deficiencies in these areas represent a major cause of their inability to advance in their desired careers in the Canadian work environment (Gill, 2012, p. 32; Jetelina, 2012; Adolphe, 2013, p. 10).

Celce-Murcia et al. (1995) point out that foreign language learning often focuses on direct speech discourse, which is insufficient, as "the majority of speech acts are most frequently realized indirectly" (Levinson, 1983, cited in Celce-Murcia et al., 1995, p. 20). Adolphe (2013) maintains that the ubiquitous use of "indirect communication styles" (p. 14) within the Canadian work environment is linked to the Canadian "conflict-averse culture" (p. 56), which reflects the Canadian norm of "show[ing] respect for others" (p. 40).

The use of direct negatives such as "no" or "I don't want to" is highly unusual (Adolphe, 2013, p. 19ff) in Canadian communication style. Non-native speakers may be unfamiliar with the indirect speech forms that are so ubiquitous in Canada, and English native-speaking Canadians might not realize the extent to which they themselves use this discursive mode for many of their interactions. Yet native speakers expect most conversational situations to be realized in an indirect "non-confrontational and modest stance" (Adolphe, 2013, p. 22) that reflects overall socio-cultural norms. Similarly, Celce-Murcia et al., $(1995$, p. 20) state that

some indirect speech acts have become so conventionalized as a result of their frequency that they no longer strike native speakers as indirect. This, however, does not hold true for non-native speakers, who often have problems understanding such conventions and therefore tend to underutilize them even at advanced levels.

For example, as Adolphe (2013) points out, the request "Would you mind doing ...?" in Canada is a common indirect form used to denote "Please do as part of your duty ..." (p. 8). In both Britain and the United States, the expression "Would you mind doing ...?" implies that the activity requested is not generally linked to the individual's work duty, denoting if you have time, if you are motivated and if you deem appropriate according to your relationship 
with the person making the request, then that request might be fulfilled. Any one of those scenarios can reflect a potentially different outcome.

Similarly, "illocutionary force", pertaining to the specific intention of what is stated, is very culturally bound (Celce-Murcia et al., 1995, p. 17). An individual from an indirect culture (e.g. Canada) will form a question in a corresponding indirect communication mode. "I'd like to look at the report once it's ready" most likely implies the speaker's intent to expect a finished report and sooner rather than later. The same intention is expressed in direct culture as "When would you have the report ready?" or even "Have you finished the report?" (which can be seen as a fairly impolite and aggressive discourse mode in prevalent Canadian indirect culture). On the other hand, the statement in direct culture "I'd like to look at the report once it's ready" conveys the speaker's intent and interest in reading the report, which is contingent on if/when the writer wishes to share the work, if/when the writer finishes the report and if/when the writer decides to allow interested parties to look at the report — factors leading to a variety of outcomes.

Classroom activities should aim to improve language competencies by enhancing student awareness of how "speech acts and language functions can be patterned and sequenced in reallife situations" (Celce-Murcia et al., 1995, p. 21) and how they reflect the social and professional environments in which students will interact. The instructor's involvement in activities (such as critical analysis, debate or discussions) helps students understand specialized content and apply language appropriately. The instructor applies the specialized course material along with corresponding activities aimed at "developing student awareness of language functions and speech acts [by] (...) present[ing] them in larger pragmatic contexts for interpretation and to emphasize their situational constraints" (p. 21).

Code (2010) states that "individuals utilize, model, and emulate behaviours (cognitive and otherwise) projected by their peers and other agents in the learning environment" (p. 113). In sociological terms, "anticipatory socialization" occurs when an individual incorporates actions and behaviors exhibited by others in accordance with the status that the individual desires (Macionis et al., 2013, p. 464; Scott and Marshall, 2009, p. 23). As Scott and Marshall have noted, this phenomenon can be seen when employees emulate the occupational attitudes, actions and behaviors of superiors to acquire promotional or financial benefits (p. 23). The author of this paper notes that "anticipatory socialization" is also reflected when non-native English speakers consciously adopt and use colloquial (informal or slang) expressions of their peers to demonstrate and affirm socio-cultural integration. However, during classroom interactions (i.e. oral and written interventions), non-native English speakers should be made aware that the use of informal speech replicating native speakers' daily or 
informal discourse is counter-productive in terms of demonstrating language competency within a formal setting. While formal verbal, structural, phrasal or logical transitions (such as "therefore", "hence", "as a result" and "accordingly") are infrequently used by native English speakers in everyday conversation, most of them know instinctively to what extent such discursive strategies should be applied in formal (spoken or written) discourse situations to convey professionalism. Within specialized courses, non-native English speakers can be given key terminology/phrases to add value to their discourse in key communicative events (interviews, meetings, presentations) that demand socio-cultural understanding of language use.

As a result of the high value placed on indirect communication style in Canada, Canadian companies often rank employees' interpersonal soft skills more highly than technical know-how, as they appreciate an individual's ability to contribute to team cohesion and harmony (Gill, 2010, pp. 46-47; Adolphe, 2013, pp. 62, 70; Jetelina, 2012). Those newcomers who are unsuccessful in obtaining employment or job promotion often lack essential communication skills specific to Canadian culture rather than technical competencies (Jetelina, 2012; Adolphe, 2013, p. 54; Holmes, 2013, pp. 49-54).

Understanding the indirect communication style employed in Canada, which reflects the Canadian "empathetic culture (...) [that puts] other people first in (...) discussions (...) out of politeness" (Adolphe, 2013, p. 6) is essential to succeeding in the professional environment. Many newcomers to Canada are faced with the challenge of developing socio-culturally relevant language competencies in order to obtain employment or career promotion (Jetelina, 2012). According to Adolphe, Canadian work culture aims to maintain a neutral, "conflict-free environment" (p. 57), and interpersonal abilities that build rapport and support among colleagues (p. 60; Jetelina, 2012) are often considered more important than employees' technical know-how when hiring or promotion is taking place (Adolphe, 2013, pp. 70-74; Jetelina, 2012). This contrasts with many direct cultures, such as in the US, where the relationship an employee builds directly with the superior or the personal ambition shown by an employee may be valued more highly than the individual's team rapport (pp. 18-19, 50). In Canada, "promotion depends almost entirely on your colleagues' feelings about you” (p. 60). Similarly, Jetelina notes that many newcomers to Canada have difficulty with soft skills, notably the indirect communication competencies required to meet the socio-cultural standards of the Canadian workplace, without which employment or advancement is difficult to obtain.

Non-native English speakers may be apprehensive about impending future "status inconsistency", defined as an individual's perceived discrepancy between academic achievements on the one hand and actual socio-economic 
standing on the other (Macionis et al., 2013, p. 468). The non-native English speaking student might anticipate a future scenario in which inadequate language competencies could result in lower socio-economic standing as compared with native-speaking colleagues with the same or lower technical skills. This anxiety can be mitigated through instructor engagement aimed at ensuring understanding of how to apply both technical language and socio-culturally relevant language, thereby enhancing students' "grit" or perseverance to develop further language competencies.

The importance of delivering soft skills in relation to the indirect cultural communication style within highly technical specialized subject matter is crucial to a student's future career development. Laroche affirms that "[t]he relative weight from technical to soft skills is about 90 to 10 in our home countries (...) But, in Canada, the relative weight placed on technical and soft skills is roughly 50/50" (Jetelina, 2012).

In this context, the instructor can develop non-native English speaking students" tenacity and "self-efficacy, [which] plays a major role in student motivation at both intrinsic and extrinsic levels" (Ernst and Clark, 2012, p. 2), promoting activities that serve dual functions, i.e. increasing specialized content knowledge and enhancing relevant socio-cultural language skills.

\section{Language competencies to enhance socio-professional integration}

Students value an instructor's ability to deliver knowledge and understanding of the industries and organizations linked to their career paths as well as of pertinent contemporary trends and events. This observation is based on the author's own assessment of over 100 student-written evaluations of their specialized course instructors over a two-year period (2013-2014). Indeed, anecdotes, news events, situations and everyday situations are important in developing social understanding of the external world along with linguistic competencies (Laroche and Rutherford, 2012, p. 90; Adolphe, 2013, pp. 22-23).

The indirect communication style so ubiquitous in Canada (Adolphe, 2013, pp. 13-18) requires a specific language adaptability to participate in everyday conversational themes, so as to avoid being "out of touch with (...) colleagues" (p. 23). Instructor-led group activities (e.g. analysis and presentations of conversational themes) can be reinforced by peer-to-peer interaction to enhance both cognitive and emotional skills for all students (Boud et al., 2013), presenting an opportunity for non-native English speakers to improve discursive techniques, expressions and specific communication styles.

Generally speaking, many non-native English speakers aspire to a status that reflects their international qualifications and work experience as well as their newly acquired Canadian credentials and work skills, given that English language capabilities and familiarity with social and cultural elements are key 
factors to realization of their goals (Jetelina, 2012).

In many cases, non-native speakers of English have attained a higher level of education and/or professional qualifications in their home countries than their native Canadian peers (Macionis et al., 2013, p. 383) but may not initially achieve the professional status they once had or that they wish to attain in Canada. The reason for this is they do not yet fully understand the dynamics of culturally relevant and, above all, neutral, i.e. "friendly and polite" (Adolphe, 2013, pp. 18, 29) Canadian communication styles (Jetelina, 2012; Adolphe, 2013, pp. 26-29; Holmes, 2013, pp. 48-52).

Accordingly, the opportunity to acquire valuable language skills within the classroom experience provides non-native English speaking students taking specialized courses with additional motivation in language acquisition so as to promote their chances for the desired rapid intra-generational mobility (i.e. the individual's own socio-professional promotion) in the new home country.

\section{Socio-cultural interaction and dynamics}

On the basis of practical experience acquired over the course of many years as a specialized course instructor with primarily non-native English speakers, the author of this paper notes that differences in social cognition, experiences, cultural backgrounds, opinions and the like can influence how students process, understand and communicate specialized terms. For example, sociology students are expected to understand the concept of "sub-culture", which refers to religious/ethnic (or other) minorities who exhibit specific cultural patterns yet are accepted within the norms and values of the dominant culture (Scott and Marshall, 2009, p. 742; Macionis et al., 2013, p. 46). In contrast, the sociological term "counter-culture" refers to minority groups perceived by the dominant culture and subcultures as outside of the accepted norms and values (Scott and Marshall 2009, p. 137; Macionis et al., 2013, pp. 46-48). The norms and values of the dominant culture determine the acceptability (or not) of minority communities, defining which groups are "subcultures" and which represent "countercultures" (Scott and Marshall, 2009, pp. 137, 742; Macionis et al., 2013, pp. 46-48).

The sociology instructor should therefore ensure that students understand specific terms and are able to apply relevant concepts correctly, notably within their future social and professional environments. For example, in Canada, same-sex couples are a sub-culture (i.e. a state-recognized minority culture) within the framework of the Canadian dominant culture, which recognizes same-sex couples as equal but different. This case in point shows the significance of conveying such specialized terminology within the appropriate socio-cultural framework, including how "subculture"-related terms are used in discourse and how they pertain to Canadian culture. Here, Canadian values 
and norms require equal treatment of sexual minority individuals in all areas of society (in contrast with many other countries where samesex couples are perceived as a counter-culture and are subjected to public discrimination and even state persecution). Ensuring that all students deliver appropriate oral and written understanding of specific terms related to socio-cultural awareness (such as subculture communities that contribute to the fabric of Canadian multi-cultural society) is important for students' future involvement in Canadian workplace culture.

As a "facilitator", the instructor conveys understanding of specialized subject matter and reinforces themes through group activities, discussions and presentations, thereby encouraging student input, individual experiences and viewpoints. This is a crucial step as "discourse, communication and (other) forms of action and interaction are (...) [influenced] by social cognition" (van Dijk, 1993, p. 257), i.e. the way in which information is retrieved, processed, and understood. Specific or complex themes, issues, and concepts that require the use of cognitive skills (logic, reason) and emotional intelligence (impartiality, objectivity) should be included to enhance specific language competencies, such as the application of discourse strategies, critical analysis and everyday discussion techniques (van Dijk, 1980; Celce-Murcia and Olshtain, 2000).

To a large extent, individual accomplishment is realized through "socially interdependent effort" (Bandura, 2001, p. 13). This is particularly true where non-native English speaking students have the dual task of developing further English language competencies along with understanding of specialized subject matter. Code's study (2010) affirms that peer-to-peer interaction (discussion, group work, case studies, critical analysis, debate) allows students in general to understand and apply terms within the learning dynamics of the classroom (pp. 79, 113). Interaction with peers through class activities gives nonnative English speaking students the opportunity to assert what Bandura (2001) calls "personal agency" through which they can "exercise some measure of control over their own functioning and over environmental events" (p. 10). Thus, students can develop and demonstrate both language skills and sociocultural understanding, including discourse appropriateness, such as when to assert "leadership" presence or a "followership" role.

Gobinder Gill, Canadian author of Achieving Prosperity through Diversity, explains: "One of the reasons many new immigrants lack such soft skills is because they are unfamiliar with the Canadian culture's day-to-day happenings" (Jetelina, 2012). Hence, discussion and analysis of concepts and issues relating to course material and subsequent application to current issues, situations, events and so forth are of value for all class participants (Code, 2010, pp. 113-114). Yet these aspects are even more important for non-native English speakers, who can gain significant communication skills that they can 
then apply to daily conversational situations in professional (or other) environments. As Adolphe (2013) states regarding "everyday conversation strategies" (p. 21) inherent to Canadian workplace culture, "if you are not prepared for these conversations $(. .$.$) you risk a great deal in your professional career (. .$. [as they] could even be the deciding factor in determining if you are a fit for that particular company" (p. 23).

\section{Conclusion: \\ Resilience, cognitive focus, progress, optimism and success}

Successful realization of the instructor's role in establishing a cohesive and rewarding classroom experience can influence the degree to which students fulfill social and professional goals. Ensuring that students have the language abilities needed to gain access to the interview stage and subsequent professional opportunities can be aided by instructor engagement to motivate non-native English-speaking students toward higher socioculturally relevant English language competencies. Activities that make up the classroom experience should combine knowledge and understanding of specialized course concepts, theories, ideas and themes, as well as awareness of socio-cultural values, standards and norms to enable students to "boundary-cross", by managing diverse communicative events in the external environment, ranging from highly specialized or technical subjects to everyday conversational themes. These aspects are linked to comprehensive language understanding and application within different communicative situations, events and settings, all of which can be promoted by the specialized course instructor through diverse and interactive classroom learning and activities.

The instructor's engagement as specialized course instructor and as English language teacher for non-native English speaking students should be conducive to a learning environment to which Bandura (2001) applies the term "collective efficacy" (p. 14), reflected in this context as positive dynamics and mutual interaction within the classroom learning environment. Students should feel confident that their respective English language competencies can be developed within the specialized course, so as to enable them to realize their social and professional aspirations.

The instructor should therefore seek to combine specialized course content with the development of culturally relevant language aptitudes for non-native speakers of English that aim to foster student "grit", i.e. perseverance and resilience, maintain cognitive focus and instill in students a sense of progress. Socio-cultural understanding, of essential features of Canadian indirect communication style in particular, should be incorporated within the specialized course activities so as to enhance non-native English speakers' opportunities for social and professional success in Canada. 


\section{References}

Adolphe, M. 2013. Canadian workplace culture: Mastering the unspoken rules. Red Deer, AB: Bold World Books.

Bandura, A. 2001. Social cognitive theory: An agentic perspective. Annual Review of Psychology, 52, pp. 1-26. Retrieved Dec. 9, 2014. Available at: www.annualreviews. org/doi/pdf/10.1146/annurev. psych.52.1.1.

Boud, D., R. Cohen and J. Sampson (eds.). 2013. Peer learning in higher education. New York: Routledge.

Brame, C.J. 2013. Flipping the classroom. Center for Teaching (CFT) Teaching Guide. Nashville: Center for Teaching, Vanderbilt University. Retrieved Dec. 9, 2014. Available at: cft.vanderbilt.edu/guides-sub-pages/flipping-the-classroom/.

Celce-Murcia, M., Z. Dörnyei and S. Thurrell. 1995. Communicative competence: A pedagogically motivated model with content specifications. Issues in Applied Linguistics, 6,2, pp. 5-35. Retrieved Dec. 9, 2014. Available at: escholarship.org/uc/item/2928w4zj.

Celce-Murcia, M. and E. Olshtain. 2000. Discourse and context in language teaching. Cambridge: Cambridge University Press.

Christensen, R. and G. Knezek. 2014. Comparative measures of grit, tenacity and perseverance. International Journal of Learning, Teaching and Educational Research, 8, pp. 16-30. Retrieved Dec. 9, 2014. Available at:

www.ijlter.org/index.php/ijter/article/view/151/0.

Code, J.R. 2010. Assessing agency for learning: Agency for learning and measuring agency for learning: Validating the Agency for Learning Questionnaire (AFLQ) and Agency as a Mediator of Academic Achievement. Doctoral dissertation, Simon Fraser University. Retrieved Dec. 9, 2014. Available at: summit.sfu.ca/system/files/ritems1/11308/etd6068_JCode.pdf.

Douglas, M. 1975. Implicit meanings. London: Routledge and Kegan Paul. Cited in Frow 1980.

Duckworth, A.L., C. Peterson, M.D. Matthews and D.R. Kelly. 2007. Grit: Perseverance and passion for long-term goals. Journal of Personality and Social Psychology, 92, pp. 1087-1101. Available at: www.sas.upenn.edu/ duckwort/images/Grit \%20JPSP.pdf.

Ernst, J.V. and A.C. Clark. 2012. Attitudes and motivation of students in an introductory technical graphics course: A meta-analysis study. Engineering Design Graphics Journal, 76,2, pp. 1-16. Retrieved Dec. 9, 2014. Available at: http://www.edgj.org/index.php/EDGJ/article/view/305.

Frow, J. 1980. Discourse genres. Journal of Literary Semantics, 9, 73-81. Retrieved Dec. 9, 2014. Available at: researchrepository. murdoch.edu.au/13399/.

Gill, G. 2010. Achieving prosperity through diversity: How to embrace, support, and lead a diverse cultural workforce. Coquitlam, BC: Profits Publishing.

Goleman, D. 2004. What makes a leader? Harvard Business Review, 82, pp. 82-91. Retrieved Dec. 9, 2014. Available at: http://hbr.org/2004/01/what-makes-a-leader/ar/1.

Holmes, P.A. 2013. Working in the Canadian workplace: Workbook: A guide for newcomers to Canda working in construction, manufacturing, service and other related 
sectors. Inisfail: Alberta Workforce Essential Skills Society (AWES). Retrieved Dec. 9, 2014. Available at:

www.awes.ca/site/assets/files/1088/working_in_the_canadian_workplace_workbook.pdf.

Jetelina, M. 2012. Improve your cultural fit, a.k.a. soft skills, for a competitive advantage. Canadian Immigrant. Retrieved Dec. 9, 2014. Available at:

canadianimmigrant.ca/slider/improve-your-cultural-fit-a-k-a-soft-skills-for-acompetitive-advantage.

Laroche, L. and D. Rutherford. 2012. Recruiting, retaining and promoting culturally different employees New York: Routledge.

Levinson, S.C. 1983. Pragmatics. Cambridge: Cambridge University Press. Cited in Celce-Murcia et al., 1995.

Macionis, J.J., S.M. Jansson and C.M. Benoit. 2013. Society: The basics. 5th Canadian ed. Toronto: Pearson Education Canada.

Neuhaus, K.J, C.J. Skube, D.G. Lee, L.A. Stevens, L.W. Hellervik and S.H. Gebelein. 2004. Successful manager's handbook: Develop yourself, Coach others. 7th ed. Minneapolis, MN: Epredix.

Preston, D.R. 1989. Sociolinguistics and second language acquisition. Oxford: Blackwell.

Scott, J. and G. Marshall. 2009. A dictionary of sociology, 3rd ed. Oxford: Oxford University Press.

Turner, L. 2006. Interlude intrigue: Student views on listening to peers in the classroom. In A. Jahek and E. Noseworthy (eds.), Atlantic Universities' Teaching Showcase Proceedings/Expo-Enseignement des universités de l'Atlantique Actes. St. John's: Memorial University of Newfoundland, pp. 145-149. Retrieved Dec. 9, 2014. Available at: http://www.atlanticuniversities.ca/sites/default/files/documents/ AAUTeachingShowcaseProceedings/2006Proceedings_replacementFinal.pdf.

Van Dijk, T.A. 1980. Discourse studies and education. Applied Linguistics, 2,1, pp. 126. Retrieved Dec. 9, 2014. Available at: applij.oxfordjournals.org/content/ll/1/1.full.pdf.

Van Dijk, T.A. 1993. Principles of critical discourse analysis. Discourse \& Society, 4,2, pp. 249-283. Retrieved Dec. 9, 2014. Available at: http://www.sfu.ca/cmns/ courses/marontate/2010/801/1-Readings/Van\%20Dijk\%20-\%20Principles\%20of\%20critical \%20discourse\%20analysis.pdf. 